\title{
Camel exposure and knowledge about MERS-CoV among Australian Hajj pilgrims in 2014
}

\section{Dear Editor,}

Middle East respiratory syndrome coronavirus (MERS$\mathrm{CoV}$ ) affected 1,621 patients worldwide, with a $36 \%$ mortality rate by the end of 2015 . The highest number of cases was recorded in Saudi Arabia, the location for Hajj pilgrimage. Hajj is the largest annual mass gathering worldwide, with 2-3 million visitors; another 5 million also visit Makkah and Madinah throughout the year for Umrah, a minor pilgrimage. MERS-CoV is transmitted to humans via camels, the only known zoonotic MERS$\mathrm{CoV}$ source. Visitors are exposed to MERS-CoV by direct contact with camels or its raw products such as milk or meat (Zumla et al., 2015). Although no MERS-CoV case has been reported among Hajj pilgrims, several cases have been found in those returning from Umrah; some of them had definite exposure to camels (Sridhar et al., 2015).

Between $35 \%$ and $65 \%$ of French, Australian, and Turkish Hajj pilgrims were unaware of MERS-CoV in Saudi Arabia (Gautret et al., 2013b; Tashani et al., 2014; Sahin et al., 2015). Importantly, no study has explored the extent of Hajj pilgrims' physical contact with camels. In this study, we evaluated departing and returning Australian pilgrims' knowledge and perceptions regarding MERS-CoV risk during Hajj, and assessed their practice regarding contact with camels.

This study involved two cross-sectional surveys among Australian pilgrims aged $\geq 18$ years, before and after Hajj in 2014. The first survey was conducted 1 month before Hajj among departing pilgrims. Participants were met at weekly pre-Hajj seminars run by travel agents and were invited to take part in the survey. The second survey was conducted immediately after the pilgrims' return to Australia (post-Hajj study). Participants were recruited in selected Muslim suburbs during community gatherings in mosques or Islamic centres. This study was reviewed and approved by the Human Research Ethics Committee (HREC) at the University of Sydney (Project No: 2014/599).

During the pre-Hajj survey, 350 (92\%) pilgrims aged 18-79 (median 39) years agreed and finally completed the survey. Over one-fifth (22\%) reported having one or more chronic diseases: $8 \%$ had diabetes, $7 \%$ asthma, $7 \%$ hypercholesterolemia and 5\% hypertension. Most pilgrims $(82 \%)$ were travelling to Hajj for the first time and planned to stay in Saudi Arabia for a median of 27 (range: 7 to 40) days.

About two-thirds of respondents (64\%) received 'travel health advice' before Hajj, including from general practitioners (GPs) (81\%), travel clinics $(24 \%)$ and specialist websites (e.g. Saudi Ministry of Health [MoH] website) (12\%). Many pilgrims consulted other individuals or sources: for example, $67 \%$ consulted Hajj tour group leaders, $46 \%$ consulted their friends and family members who had previously attended Hajj, and $17 \%$ browsed 'general websites'.

About half of the participants (49\%) knew about MERS-CoV before travelling to Saudi Arabia; of these, $70 \%$ reported mass media as the main information source. Demographic factors significantly associated with MERS-CoV knowledge were female gender, age > 40 years, and Middle Eastern origin (Table 1). Receipt of pre-travel advice from their GPs (odds ratio [OR] 1.6, 95\% confidence interval $[\mathrm{CI}] 1.0-2.4, P=0.03$ ) or from Hajj tour group leaders (OR 1.6, 95\% CI 1.0-2.5, $P=$ 0.04 ) were also significantly associated with MERS-CoV awareness (Table 1).

Of those aware of the disease, $77 \%$ answered correctly that the virus affects the respiratory system whereas $60 \%$ thought the disease was serious only for the elderly. Furthermore, $48 \%$ of pilgrims who knew about the disease reported that they were either "not concerned" or "slightly concerned" about contracting the disease during Hajj. Half (51\%) of the respondents were aware of the Saudi MoH advice for 'at risk' individuals to postpone Hajj that year; however, none of these 'at risk' individuals adhered to this recommendation (Table 2).

Participants were acceptable with using preventive measures during Hajj for protection from MERS-CoV infection: $79 \%$ were willing to wash hands frequently, $73 \%$ planned to avoid contact with sick people showing symptoms of a respiratory infection, $65 \%$ were willing to use facemasks, and another $65 \%$ planned to avoid touching their eyes, nose, and mouth.

Most departing pilgrims (62\%) were aware of a mod- 
Table 1. Pre-Hajj survey in $2014(n=350)$ : participants' demographic characteristics and knowledge about MERS-CoV.

\begin{tabular}{|c|c|c|c|c|}
\hline Factors & $N(\%)$ & Had MERS-CoV knowledge (\%) & $\mathrm{OR}^{*}\left(95 \% \mathrm{Cl}^{* *}\right)$ & $P$ value \\
\hline \multicolumn{5}{|c|}{ Age, years } \\
\hline $18-40$ & $178(51)$ & $77(43)$ & Reference & \\
\hline$>40$ & $172(49)$ & $102(59)$ & $2(1.3-3.1)$ & $<0.01$ \\
\hline \multicolumn{5}{|l|}{ Gender } \\
\hline Male & $213(61)$ & $96(48)$ & Reference & \\
\hline Female & $137(39)$ & $77(60)$ & $1.6(1.0-2.4)$ & 0.04 \\
\hline \multicolumn{5}{|c|}{ Middle Eastern origin } \\
\hline No & $240(67)$ & $103(43)$ & Reference & \\
\hline Yes & $110(31)$ & $71(65)$ & $2.42(1.5-4.0)$ & $<0.01$ \\
\hline \multicolumn{5}{|c|}{ Employed } \\
\hline No & $120(33)$ & $54(45)$ & Reference & \\
\hline Yes & $230(67)$ & $113(49)$ & $1.17(0.9-1.7)$ & 0.66 \\
\hline \multicolumn{5}{|c|}{ Presence of comorbidities } \\
\hline No & $274(78)$ & $130(47)$ & Reference & \\
\hline Yes & $76(22)$ & $43(57)$ & $0.69(0.6-1.6)$ & 0.87 \\
\hline
\end{tabular}

Note: ${ }^{*} \mathrm{OR}=$ odds ratio; ${ }^{* *} \mathrm{Cl}=$ confidence interval; Bold values indicate a significant difference.

erate to high infection risk from raw camel milk consumption, yet $21 \%$ of participants were willing to drink it. Additionally, $27 \%$ of participants were willing to visit a camel farm during Hajj, or at least stated the possibility of doing so. Pilgrims who knew about MERS-CoV were significantly more aware of the risks of MERSCoV from drinking unpasteurized camel milk compared to those who did not know ( $43 \%$ vs. $23 \%, P<0.01$ ). Nevertheless, among those who were aware of MERS$\mathrm{CoV}, 27 \%$ did not fully realize the risk of catching the disease from unpasteurized camel milk, $15 \%$ were willing to drink raw camel milk, and 23\% were keen to visit camel farm in Saudi Arabia (Table 3).

For the second survey, 150 returning pilgrims aged 18-72 (median 41) years were recruited after Hajj; 47\% were men, and $16 \%$ reported having one or more chronic diseases: $6 \%$ had asthma, 3\% diabetes mellitus, $2 \%$ malignancies, and 5\% had other conditions. Most participants $(71 \%)$ had up to high school education level, $65 \%$ were employed, and $77 \%$ went for Hajj for the first time; the median duration of stay at Hajj was 25 (range: 7 to 35 ) days. Of 150 pilgrims, $7 \%$ reported having actual contact with camels (e.g. taking photographs with camels), or consuming camel products, including meat $(5 \%)$ and unpasteurized milk (1.3\%).

Although this was the third year of MERS-CoV circulating in Saudi Arabia, only 50\% Australian departing pilgrims knew about the disease. However, this was a clear improvement compared to the findings of another
Australian survey conducted a few months earlier (only $35 \%$ pilgrims were aware of MERS-CoV in Saudi Arabia) (Tashani et al., 2014). Compared to the Ebola outbreak in 2014 about which 90\% Australian Hajj pilgrims were aware (Alqahtani et al., 2015b), fewer pilgrims were aware of MERS-CoV. The Ebola outbreak severity with consequent wider media coverage probably played a role in increasing awareness. For instance, Ebola has affected over 28,640 people with a relatively higher fatality rate $(40 \%)$ compared to fewer MERS-CoV cases (about 1,621 ) and a slightly lower fatality rate $(36 \%)$ (WHO, 2015).

In this study, $62 \%$ of departing pilgrims were aware of the risk of contracting the disease from drinking raw camel milk while $21 \%$ were willing to drink camel milk if offered at Hajj. This contrasts with the findings of Gautret et al. who showed that only 14\% French pilgrims knew about the disease risk from drinking raw camel milk but $40 \%$ of them were willing to drink camel milk if offered during Hajj (Gautret et al., 2013a), indicating that pilgrims' awareness influenced their attitude. A unique finding to emerge from our study was that departing pilgrims with knowledge about MERS-CoV were significantly more aware of the risk of drinking raw camel milk $(43 \%$ vs. $23 \%, P<0.01)$, yet a considerable proportions of them were willingness to drink raw milk and visit camel farms (respectively $15 \%$ and $23 \%$ ). This possibly indicates that despite being aware of MERS$\mathrm{CoV}$ epidemic in Saudi Arabia, some individuals were 
Table 2. Pre-Haij survey in $2014(n=350)$ : participants' knowledge and attitude regarding MERS-CoV.

\begin{tabular}{|c|c|}
\hline Traits & Number $(\%)$ \\
\hline Have awareness of MERS-CoV & $173(49)$ \\
\hline \multicolumn{2}{|l|}{ Source of knowledge* } \\
\hline Mass media & $121(70)$ \\
\hline Internet & $34(20)$ \\
\hline Family \& friends & $32(18)$ \\
\hline GPs & $27(16)$ \\
\hline Travel agents & $11(6)$ \\
\hline Saudi MoH & $8(5)$ \\
\hline 'Smarttraveller' website** & $8(5)$ \\
\hline Other sources & $3(2)$ \\
\hline \multicolumn{2}{|l|}{ Severity of MERS-CoV } \\
\hline \multicolumn{2}{|l|}{ For pilgrims aged $\geq 65$ years ${ }^{* * *}$} \\
\hline Very serious & $100(60)$ \\
\hline Moderately serious & $43(25)$ \\
\hline Slightly serious & $14(8)$ \\
\hline Not serious & $11(6)$ \\
\hline \multicolumn{2}{|c|}{ For pilgrims with chronic diseases ${ }^{* * *}$} \\
\hline Very serious & $86(51)$ \\
\hline Moderately serious & $48(28)$ \\
\hline Slightly serious & $15(9)$ \\
\hline Not serious & $20(12)$ \\
\hline \multicolumn{2}{|c|}{ For pilgrims aged between (18-64) years } \\
\hline Very serious & $47(27)$ \\
\hline Moderately serious & $43(25)$ \\
\hline Slightly serious & $47(27)$ \\
\hline Not serious & $36(21)$ \\
\hline \multicolumn{2}{|c|}{ Risk of contracting MERS-CoV at Hajj } \\
\hline Very concerned & $47(27)$ \\
\hline Moderately concerned & $43(25)$ \\
\hline Slightly concerned & $47(27)$ \\
\hline Not concerned & $36(21)$ \\
\hline \multicolumn{2}{|c|}{ Awareness about MoH guidance to postpone Hajj } \\
\hline Yes & $88(51)$ \\
\hline No & $85(49)$ \\
\hline \multicolumn{2}{|c|}{ Knowledge about body part affected by MERS-CoV ${ }^{* * *}$} \\
\hline Respiratory tract & $132(77)$ \\
\hline Kidneys & $16(9)$ \\
\hline Digestive tract & $12(7)$ \\
\hline Brain & $11(6)$ \\
\hline
\end{tabular}

Note: *Some pilgrims obtained the information from more than one sources, so the percentage is $>100$; ${ }^{* *}$ smartraveller.gov. au; ${ }^{* \star *}$ Missing data have been excluded. not fully informed about the high risk behaviors (AlMohrej et al., 2015). This could be addressed by public awareness campaigns. Providing direct health education to Hajj pilgrims at entry points (e.g. airport) in Saudi Arabia could improve their understanding about the possible modes of transmission of MERS-CoV and how to avoid exposure risks (Turkestani et al., 2013).

In practice, about $7 \%$ of returning pilgrims reported actually coming in close contact with camels and $1.3 \%$ drank unpasteurized camel milk. This is unsurprising considering that about $8 \%$ French Hajj pilgrims had a history of consuming raw camel milk in North Africa and Saudi Arabia (Gautret et al., 2013a). An iPhone appbased small survey conducted parallel to this survey revealed that $16 \%$ of international Hajj pilgrims reported contact with camels during Hajj (Alqahtani et al., 2015a). Consumption of raw camel products (milk, liver, meat, or urine) can lead to outbreaks of other infections such as brucellosis, plague, and rift valley fever (Bin Saeed et al., 2005; Davies, 2006; Kalimuddin et al., 2010). Therefore, pilgrims who consume raw milk or other products are at risk of other zoonotic diseases if not MERS-CoV, and therefore, could benefit from appropriate health education.

The current MERS-CoV guidelines by Saudi MoH stated that any person with close contact with camels (in the last 14 days), including drinking unpasteurized camel milk and showing respiratory symptoms, is suspected with MERS-CoV (CCC, 2015). The recent outbreak in South Korea, worsened by the initial failure of heath care providers to recognize the infection, shows the importance of early recognition of symptoms of MERS-CoV (Kim and Lee, 2015). To prevent virus introduction to their lands, some countries (e.g. the UK) have issued a set of guidelines for managing suspected MERS-CoV cases (Kumar et al., 2015), which is exemplary (PHE, 2015). Given that 7\% people reported having close contact with camels, we suggest development of a public health strategy to better communicate the risk to pilgrims and information about when to seek medical help should symptoms arise upon return.

Over half of the departing pilgrims were aware of the Saudi MoH advice to postpone Hajj; nevertheless, none of the high-risk pilgrims decided to cancel their trip. This is consistent with the findings of French researchers who also discovered that none of the at-risk pilgrims had planned to postpone their trip (Gautret et al., 2013b).

As mass media was the main source of MERS-CoV knowledge, we believe mainstream media outlets (e.g. TV) should be used to propagate heath messages immediately before, during, and after the Hajj season. Tour group leaders can also play an important role in disseminating health advice, as shown here and previously (Alqahtani et al., 2015b). 
Table 3. Pre-Hajj survey in 2014: participants' perceptions about the risk of camel exposure at Hajj.

Pilgrims aware of

MERS-CoV n (\%)*

Pilgrims unaware of MERS-CoV n $(\%)^{* *}$

$P$ value

\begin{tabular}{llll}
\hline Risk of drinking unpasteurized camel milk & & & $<$ \\
No risk & $23(13)$ & $41(23)$ & \\
Low risk & $25(14)$ & $43(24)$ & \\
Medium risk & $50(30)$ & $53(30)$ & \\
High risk & $75(43)$ & $40(23)$ & $\mathbf{0 . 0 4}$ \\
Willing to drink unpasteurized camel milk & & & \\
Definitely not & $100(58)$ & $82(46)$ & \\
Unlikely & $46(27)$ & $49(28)$ & \\
Possibly & $25(14)$ & $39(22)$ & 0.18 \\
Definitely yes & $2(1)$ & $7(4)$ & \\
Willing to visit camel farm & & $66(37)$ & \\
Definitely not & $83(48)$ & $54(31)$ & \\
Unlikely & $51(30)$ & $48(27)$ & $9(5)$ \\
Possibly & $33(19)$ & $7(4)$ & \\
Definitely yes & & \\
\hline
\end{tabular}

Note: *Number of pilgrims $=173 ;{ }^{* \star}$ Number of pilgrims $=177 ;$ Bold values denote significant difference.

In conclusion, many Australian Hajj pilgrims are not aware of MERS-CoV in Saudi Arabia, and some of them engage in activities that may put them at risk of MERS$\mathrm{CoV}$; therefore, there is a need for improved awareness among Hajj pilgrims and other travelers to the Middle East regarding MERS-CoV.

\section{FOOTNOTES}

Professor Robert Booy has received funding from Baxter, CSL, GSK, Merck, Novartis, Pfizer, Roche, Romark and Sanofi Pasteur for conducting this research, travelling to conferences or consultancy work; all funding received is directed to research accounts at The Children's Hospital at Westmead. Dr. Anita E. Heywood has received grant funding from GSK and Sanofi Pasteur for investigator-driven research. Dr. Harunor Rashid has received fees from Pfizer and Novartis for consulting or serving on an advisory board. The other authors have no competing interests to declare. Informed consent was obtained from all participants.

Amani Salem Alqahtani ${ }^{1,2 \bowtie}$, Kerrie Elizabeth Wiley ${ }^{1,2}$, Mohamed Tashani ${ }^{1}$, Anita Elizabeth Heywood ${ }^{3}$, Harold Wayne Willaby', Nasser Fahad BinDhim ${ }^{4}$, Robert Booy ${ }^{1,5,6}$, Harunor Rashid ${ }^{1,5}$

1. National Centre for Immunisation Research and Surveillance of Vaccine Preventable Diseases (NCIRS), The Children's Hospital at Westmead, and the Discipline of Paediatrics and Child Health, Sydney Medical School, The University of Sydney, Sydney, NSW 2145, Australia

2. School of Public Health, The University of Sydney, Sydney, NSW 2006, Australia

3. School of Public Health and Community Medicine, The University of New South Wales, Sydney, NSW 2033, Australia

4. Health Informatics Department, College of Health Sciences, Saudi Electronic University, Riyadh 11461, Saudi Arabia

5. Marie Bashir Institute for Infectious Diseases and Biosecurity, School of Biological Sciences and Sydney Medical School, University of Sydney, Sydney, NSW 2145, Australia

6. WHO Collaborating Centre for Mass Gatherings and High Consequence/High Visibility Events, Flinders University, Adelaide 5001, Australia

$\triangle$ Correspondence:

Phone: +61-401184575, Fax: +61-2-98451418,

Email: amani.alqahtani@health.nsw.gov.au

ORCID: 0000-0001-9459-4863

Published online: 18 January 2016

\section{REFERENCES}

Al-Mohrej OA, Al-Shirian SD, Al-Otaibi SK, et al. 2015. J Infect Public Health. Doi: 10.1016/ j.jiph.2015.10.003.

Alqahtani AS, BinDhim NF, Tashani M, et al. 2015a. J Epidemiol Glob 
Health. Doi: 10.1016/j.jegh.2015.07.005

Alqahtani AS, Wiley KE, Willaby HW, et al. 2015b. Euro Surveill, 20: pii $=21072$.

Bin Saeed AA, Al-Hamdan NA, Fontaine RE. 2005. Emerg Infect Dis, 11: 1456-1457.

Command and Control Center Ministry of Health Kingdom of Saudi Arabia (CCC), 2015.Infection Prevention and Control Guidelines for Middle East Respiratory Syndrome Coronavirus (MERS-CoV) Infection, 3rd edition. Available: http://www.moh.gov.sa/Documents/ 2015\%20update.pdf

Davies FG. 2006. Rev Sci Tech, 25: 137-147.

Gautret P, Benkouiten S, Gaillard C, et al. 2013a. Vector Borne Zoonotic Dis, 13: 425-427.

Gautret P, Benkouiten S, Salaheddine I, et al. 2013b. Euro Surveill, 18: 20604.

Kalimuddin S, Seow CJ, Barkham T, et al. 2010. Scand J Infect Dis, 42:
228-230.

Kim TH, Lee HH. 2015. J Menopausal Med, 21: 63-64.

Kumar A, Beckett G, Wiselka M. 2015. BMJ, 351: h5185.

Public Health England (PHE), 2015. MERS, influenza and respiratory illness in travellers returning from the Hajj. Available: https://www. gov.uk/government/publications/health-protection-report-volume-92015/hpr-volume-9-issue-36-news-9-october. Accessed 29 December 2015.

Sahin MK, Aker S, Kaynar Tuncel E. 2015. Euro Surveill. Doi: 10.2807/1560-7917.ES.2015.20.38.30023.

Sridhar S, Brouqui P, Parola P, et al. 2015. Travel Med Infect Dis, 13: 106-109.

Turkestani A, Balahmar M, Ibrahem A, et al. 2013. East Mediterr Health J, 19: S9-12. PMID: 24673092.

Tashani M, Alfelali M, Barasheed O, et al. 2014. Virol Sin, 29: 318-320.

Zumla A, Hui DS, Perlman S. 2015. Lancet, 386: 995-1007. 